\title{
Genetic and Environmental Stability of Neuroticism From Adolescence to Adulthood
}

\author{
Michel G. Nivard, ${ }^{1}$ Christel M. Middeldorp, ${ }^{1,2}$ Conor V. Dolan, ${ }^{1}$ and Dorret I. Boomsma ${ }^{1,2,3}$ \\ ${ }^{1}$ Department of Biological Psychology, VU University Amsterdam, the Netherlands \\ ${ }^{2}$ Neuroscience Campus Amsterdam, Amsterdam, the Netherlands \\ ${ }^{3} \mathrm{EMGO}^{+}$Institute for Health and Care Research, Amsterdam, the Netherlands
}

\begin{abstract}
Longitudinal studies of neuroticism have shown that, on average, neuroticism scores decrease from adolescence to adulthood. The heritability of neuroticism is estimated between 0.30 and 0.60 and does not seem to vary greatly as a function of age. Shared environmental effects are rarely reported. Less is known about the role of genetic and environmental influences on the rank order stability of neuroticism in the period from adolescence to adulthood. We studied the stability of neuroticism in a cohort sequential (classical) twin design, from adolescence (age 14 years) to young adulthood (age 32 years). A genetic simplex model that was fitted to the longitudinal neuroticism data showed that the genetic stability of neuroticism was relatively high (genetic correlations between adjacent age bins $>0.9$ ), and increased from adolescence to adulthood. Environmental stability was appreciably lower (environmental correlations between adjacent age bins were between 0.3 and 0.6 ). This low stability was largely due to age-specific environmental variance, which was dominated by measurement error. This attenuated the age-to-age environmental correlations. We constructed an environmental covariance matrix corrected for this error, under the strong assumption that all age-specific environmental variance is error variance. The environmental (co)variance matrix corrected for attenuation revealed highly stable environmental influences on neuroticism (correlations between adjacent age bins were between 0.7 and 0.9 ). Our results indicate that both genetic and environmental influences have enduring effects on individual differences in neuroticism.
\end{abstract}

Keywords: personality, stable environmental influences, genetic correlation, simplex models

Neuroticism is included in nearly all trait theories of personality (see Digman, 1990) and has been established as a universal (i.e., not bound to any particular culture) trait in cross-cultural studies (McCrae \& Costa Jr, 1997; Schmitt et al., 2007). While the term trait conveys the conceptualization of personality as stable, it is known that personality scores change over the lifespan (McCrae et al., 1999; Soto et al., 2011) and between cohorts (Smits et al., 2011). A meta-analysis of longitudinal studies revealed that the mean score of neuroticism decreases between age 12 and 40 years, and remains largely stable thereafter (Roberts et al., 2006). In addition, the stability of individual differences in neuroticism is characterized by an increase in rank order stability up until age 60 , with a decrease in stability observed after age 60 (Roberts \& DelVecchio, 2000).

Neuroticism is associated with mood and anxiety disorders (Clark et al., 1994; Enns \& Cox, 1997; Kendler et al., 1993; Middeldorp et al., 2006; Roberts \& Kendler, 1999). This association is partly due to pleiotropic genetic influences (Jardine et al., 1984; Kendler et al., 1993; Mackin- tosh et al., 2006; Middeldorp et al., 2005; 2011; Roberts \& Kendler, 1999). Genetic pleiotropy also accounts for the association between neuroticism and borderline personality disorder (Distel et al., 2009). Neuroticism also has a moderate genetic correlation with somatic and neurological disorders such as migraine (Ligthart \& Boomsma, 2012). The heritability of neuroticism has been estimated between $30 \%$ and $60 \%$. There is little or no evidence for common environmental influences shared by family members, which is consistent with the lack of cultural transmission from parents to offspring (Lake et al., 2000). There is some evidence for non-additive genetic effects (Birley et al., 2006; FloderusMyrhed et al., 1980; Keller et al., 2005; Lake et al., 2000;

RECEIVED 24 September 2015; ACCEPTED 1 October 2015. First published online 20 November 2015.

ADDRESS FOR CORRESPONDENCE: Michel G. Nivard, Department of Biological Psychology, VU University Amsterdam, Van der Boechorststraat 1, 1081BT Amsterdam, the Netherlands. E-mail: m.g.nivard@vu.nl 
Loehlin et al., 1998; Rettew et al., 2006; van den Berg et al., 2014; Vukasović \& Bratko, 2015). Eaves et al. (1998) suggested that this is more likely to be attributable to epistatic interaction (i.e., interaction between alleles at different genetic loci) rather than to genetic dominance (interaction within a genetic locus).

Rettew et al. (2006) found little evidence for quantitative changes in genetic or environmental variance in neuroticism between ages 12 and 17. Wray et al. (2007; see also Birley et al., 2006) reported genetic correlations across 22 years between 0.82 and 0.95 , and environmental correlations between 0.24 and 0.53 . These twin studies focused on correlations in neuroticism scores between measurement occasions. However, at each measurement occasion, the participants varied appreciably in age, which introduces possible age-related heterogeneity in genetic and environmental effects. In contrast, Viken et al. (1994) collected two repeated measures of neuroticism, six years apart, in twin pairs aged between 18 and 59 years, but reordered the data as a function of chronological age at first measurement. Viken et al. (1994) reported high genetic correlations (between 0.8 and 1 ), and low to moderate environmental correlations (between 0.25 and 0.54 ) between chronological ages. Briley and Tucker-Drob (2014) recently reported a metaanalysis of genetic studies of personality, with the age of twin and sibling pairs ranging from infancy to old age. Their study included neuroticism, well-being, and measures of psychopathology, such as aggression and inattention. They found that both the genetic and environmental stability increased with age. They reported a substantially higher environmental stability when they corrected for measurement error.

In the current twin study, we analyzed repeated measures of neuroticism assessed between ages 14 and 32 years. Our aim was to further elucidate the increase in the rank stability of neuroticism from adolescence to young adulthood, a period marked by a mean decrease in neuroticism. We worked with age bins comprising two years, which provided greater resolution of the changes in genetic and environmental stability than that provided in previous work (Viken et al., 1994). In addition to estimating genetic and environmental correlations across age, we addressed the effect of measurement error on the estimation of the environmental correlations between repeated neuroticism measures. Briley and Tucker-Drob (2014) corrected the (unshared) environmental variance for measurement error by quantifying the proportion of measurement error variance (1- $\alpha)$ using Cronbach's $\alpha$. Here, we accounted for measurement error by fitting a simplex (or autoregressive) model to longitudinal twin data (Boomsma \& Molenaar, 1987). In this model, we distinguish between genetic and environment variance involved in the auto-regression, and occasion specific (transient) genetic and environmental variance. We assume that age specific unshared environmental variance is largely due to measurement error.

\section{Methods}

\section{Subjects and Measures}

We analyzed the data of monozygotic (MZ) and dizygotic (DZ) twins in the Netherlands Twin Register (NTR). NTR participants were initially approached via city councils and later by other means (Willemsen et al., 2013). Participants were invited, at multiple occasions, to fill out and return a set of surveys, which included a neuroticism questionnaire. Since our main interest is in the stability of neuroticism between adolescence and adulthood, we focused on data from twins aged from 14 to 32 . Neuroticism was assessed in 1991, $1995,1997,2000$, and 2002. We reordered the data from the different surveys into nine age bins, each spanning two years (i.e., 14-15, 16-17, . , 28-29, 30-31). The dataset comprised 15,275 observations on 6,943 twins, including 1,392 complete MZ twin pairs and 1,826 complete DZ twin pairs. Table 1 contains the number of observations in each age bin. The number of overlapping samples between adjacent age batches is substantial, but drops off with the distance between the age batches. In view of this missingness, we used full information maximum-likelihood (FIML) estimation, under the assumption that the data are missing (completely) at random. We fitted all models in Mplus 6.11 using FIML. We compared competing models on the basis of Akaike's information criterion (AIC), Bayes information criterion (BIC) and sample size adjusted Bayes information criterion (SA-BIC).

Neuroticism was assessed using the Amsterdamsche Biografische Vragenlijst (ABV; Wilde, 1970; i.e., the Amsterdam Biographic Questionnaire). The ABV neuroticism scale $(\mathrm{ABV}-\mathrm{N})$ was modeled on the Eysenck Personality Questionnaire (EPQ). The ABV-N is a 30 -item instrument that contains questions like 'Do you often worry about the past?' The response options are 'yes', 'no' and '?. Following the ABV test manual, item responses were weighted in calculating the neuroticism sum score (Wilde, 1970). Table 1 contains the ABV-N means and standard deviations by age and sex. Van den Berg et al. (2014) compared the ABV-N and other neuroticism scales and reported a large overlap in item content, and a high correlation (0.89) between the ABV-N and the IRT neuroticism scores.

\section{Statistical Model}

At each age, we modeled the neuroticism score using the Simplex model. The neuroticism score at time t was modeled as follows (discarding subject subscripts):

$$
y_{t}=\beta_{0 t}+\beta_{s t} * s e x+A_{t}+D_{t}+E_{t}+\tau_{A t}+\tau_{D t}+\tau_{E t}
$$

In equation $1, \beta_{0 t}$ is the occasions specific intercept, $\beta_{\mathrm{st}}$ is the occasion specific sex effect, and $\tau_{\mathrm{At}}, \tau_{\mathrm{Dt}}$, and $\tau_{\mathrm{Et}}$ are (zero mean) occasion-specific additive genetic, dominance, and unshared environmental variables. We assume that $\tau_{\mathrm{Et}}$ largely due to measurement error. The (zero mean) additive genetic, dominance, and unshared environmental variables 


\begin{tabular}{|c|c|c|c|c|c|c|c|c|c|}
\hline Age bins & $14-15$ & $16-17$ & $18-19$ & $20-21$ & $22-23$ & $24-25$ & $26-27$ & $28-29$ & $30-31$ \\
\hline 14-15 & 1,583 & 491 & 430 & 486 & 381 & 418 & 221 & 7 & 0 \\
\hline $16-17$ & 0.62 & 2,263 & 576 & 624 & 805 & 409 & 505 & 310 & 12 \\
\hline $18-19$ & 0.61 & 0.61 & 2,278 & 574 & 669 & 663 & 364 & 433 & 263 \\
\hline $20-21$ & 0.45 & 0.64 & 0.67 & 2,258 & 707 & 550 & 553 & 284 & 325 \\
\hline $22-23$ & 0.38 & 0.53 & 0.65 & 0.69 & 2,038 & 417 & 445 & 359 & 132 \\
\hline $24-25$ & 0.46 & 0.56 & 0.58 & 0.68 & 0.75 & 1,553 & 356 & 268 & 226 \\
\hline $26-27$ & 0.42 & 0.52 & 0.60 & 0.60 & 0.72 & 0.76 & 1,297 & 318 & 180 \\
\hline $28-29$ & -0.23 & 0.45 & 0.53 & 0.56 & 0.65 & 0.76 & 0.76 & 1,050 & 232 \\
\hline $30-31$ & $N A$ & 0.71 & 0.53 & 0.57 & 0.54 & 0.67 & 0.73 & 0.77 & 810 \\
\hline \multicolumn{10}{|l|}{ Twin correlations } \\
\hline MZ correlations & 0.61 & 0.61 & 0.55 & 0.53 & 0.53 & 0.47 & 0.50 & 0.57 & 0.51 \\
\hline DZ correlations & 0.27 & 0.29 & 0.26 & 0.27 & 0.23 & 0.19 & 0.29 & 0.17 & 0.10 \\
\hline ABV-N mean and $S D$ & Males & & & & & & & & \\
\hline Mean & 50.62 & 49.08 & 46.40 & 46.37 & 43.04 & 42.78 & 41.12 & 40.05 & 37.79 \\
\hline \multirow[t]{2}{*}{$S D$} & 21.63 & 21.57 & 21.58 & 22.66 & 22.49 & 22.38 & 23.06 & 22.17 & 21.60 \\
\hline & Females & & & & & & & & \\
\hline Mean & 58.02 & 58.35 & 58.34 & 55.69 & 53.03 & 53.26 & 50.84 & 49.62 & 49.58 \\
\hline$S D$ & 23.19 & 23.90 & 24.52 & 24.70 & 24.94 & 26.45 & 25.19 & 25.15 & 25.26 \\
\hline
\end{tabular}

$A_{t}, D_{t}$, and $E_{t}$ are decomposed into a part due to transmission of effects from earlier ages and a part due to innovation:

$$
\begin{aligned}
& \mathrm{A}_{\mathrm{t}}=\beta_{\mathrm{At}} * \mathrm{~A}_{\mathrm{t}-1}+\zeta_{\mathrm{At}}, \\
& \mathrm{D}_{\mathrm{t}}=\beta_{\mathrm{Dt}} * \mathrm{D}_{\mathrm{t}-1}+\zeta_{\mathrm{Dt}}, \\
& \mathrm{E}_{\mathrm{t}}=\beta_{\mathrm{Et}} * \mathrm{E}_{\mathrm{t}-1}+\zeta_{\mathrm{Et}} .
\end{aligned}
$$

In equation $2, \beta_{\mathrm{At}}$ is the auto-regression coefficient, and $\zeta_{A t}$ is the innovation, that is, the residual in the regression of $A_{t}$ on $A_{t-1}$ (the same interpretation applies to equations 3 and 4$)$. Note that at $\mathrm{t}=1$, we set $\mathrm{A}_{1}=\zeta_{\mathrm{A} 1}, \mathrm{D}_{1}=\zeta_{\mathrm{D} 1}$, and $\mathrm{E}_{1}=$ $\zeta_{\mathrm{E} 1}$. While we included sex-related mean differences at each occasion $\left(\beta_{\mathrm{st}}\right)$, we imposed a single (genetic) covariance model in the male and females twins, as large studies found no evidence for moderation of effects by gender (van den Berg et al., 2014; Vukasović \& Bratko, 2015).

The equations $1-4$ give rise to the following $9 \times 9$ covariance structure matrices:

$$
\begin{aligned}
& \Sigma_{\mathrm{A}}=\left(\mathrm{I}-\mathrm{B}_{\mathrm{A}}\right)^{-1} \Psi_{\mathrm{A}}\left(\mathrm{I}-\mathrm{B}_{\mathrm{A}}\right)^{-1^{\mathrm{t}}}+\Theta_{\mathrm{A}}, \\
& \Sigma_{\mathrm{D}}=\left(\mathrm{I}-\mathrm{B}_{\mathrm{D}}\right)^{-1} \Psi_{\mathrm{D}}\left(\mathrm{I}-\mathrm{B}_{\mathrm{D}}\right)^{-1^{\mathrm{t}}}+\Theta_{\mathrm{D}}, \\
& \Sigma_{\mathrm{E}}=\left(\mathrm{I}-\mathrm{B}_{\mathrm{E}}\right)^{-1} \Psi_{\mathrm{E}}\left(\mathrm{I}-\mathrm{B}_{\mathrm{E}}\right)^{-1^{\mathrm{t}}}+\Theta_{\mathrm{E}},
\end{aligned}
$$

where $I$ is the $9 \times 9$ identify matrix, $B_{A}(9 \times 9)$ contains the autoregressive coefficients $\beta_{\text {At }}(t=2,9)$, the diagonal covariance matrix $(9 \times 9) \Psi_{\mathrm{A}}$ contains the variance $\left(\mathrm{A}_{1}\right)(\mathrm{t}=$ $1)$, and the variances $\operatorname{var}\left(\zeta_{\mathrm{At}}\right)(\mathrm{t}=2,9)$, and the diagonal covariance matrix $(9 \times 9) \Theta_{\mathrm{A}}$ contains the variance of $\tau_{\mathrm{At}}$ $(t=1,9)$. Equations 6 and 7 are defined analogously. Note that the first and the last variances (e.g., in the matrix $\Theta_{A}$, $\operatorname{var}\left[\tau_{A 1}\right]$ and $\left.\operatorname{var}\left[\tau_{A 9}\right]\right)$ are not identified. Identification is achieved by fixing these variances to zero, or constraining them to be equal to the adjacent variances. Below we adopted the latter constraint in the specification of $\Theta_{A}, \Theta_{D}$, and $\Theta_{\mathrm{E}}$. In MZ and DZ twin samples, the expected $18 \times 18$ partitioned covariance matrices are

$$
\begin{aligned}
& \Sigma_{A}+\Sigma_{D}+\Sigma_{E} \quad \Sigma_{A}+\Sigma_{D} \\
& \Sigma_{\mathrm{MZ}}=\Sigma_{A}+\Sigma_{D} \quad \Sigma_{A}+\Sigma_{D}+\Sigma_{E} \text {, } \\
& \Sigma_{\mathrm{A}}+\Sigma_{\mathrm{D}}+\Sigma_{\mathrm{E}} 1 / 2 \Sigma_{\mathrm{A}}+1 / 4 \Sigma_{\mathrm{D}} \\
& \Sigma_{\mathrm{DZ}}=1 / 2 \Sigma_{\mathrm{A}}+1 / 4 \Sigma_{\mathrm{D}} \quad \Sigma_{\mathrm{A}}+\Sigma_{\mathrm{D}}+\Sigma_{\mathrm{E}} \text {, }
\end{aligned}
$$

where the weights $1 / 2$ and $1 / 4$ follow from quantitative genetic theory given a set of explicit assumptions, including random mating, which has been found to be tenable with respect to neuroticism (Eaves et al., 1998), and the absence of interaction and covariance among the genetic and environmental variables.

We expressed the unshared environmental covariance matrix corrected for attenuation due to measurement error as follows:

$$
\Sigma_{\mathrm{E}-\mathrm{dis}}=\left(\mathrm{I}-\mathrm{B}_{\mathrm{E}}\right)^{-1} \Psi_{\mathrm{E}}\left(\mathrm{I}-\mathrm{B}_{\mathrm{E}}\right)^{-1^{\mathrm{t}}} .
$$

This is based on the strong assumption that the variance in the matrix $\Theta_{\mathrm{E}}$ is dominated by measurement error. Note that the uncorrected environmental correlation between ages $\mathrm{t}-1$ and $\mathrm{t}$ is

$$
\begin{aligned}
& {\left[\beta_{\mathrm{Et}} * \operatorname{var}\left(\mathrm{E}_{\mathrm{t}-1}\right)\right] /\left[\left\{\operatorname{var}\left(\mathrm{E}_{\mathrm{t}-1}\right)+\operatorname{var}\left(\mathrm{t}_{\mathrm{Et}-1}\right)\right\}^{1 / 2}\right.} \\
& \left.\quad \times *\left\{\beta_{\mathrm{Et}}^{2} * \operatorname{var}\left(\mathrm{E}_{\mathrm{t}-1}\right)+\operatorname{var}\left(\zeta_{\mathrm{Et}}\right)+\operatorname{var}\left(\tau_{\mathrm{Et}}\right)\right\}^{1 / 2}\right],
\end{aligned}
$$

and the corrected correlation is

$$
\begin{aligned}
& {\left[\beta_{\mathrm{Et}} * \operatorname{var}\left(\mathrm{E}_{\mathrm{t}-1}\right)\right] /\left[\left\{\operatorname{var}\left(\mathrm{E}_{\mathrm{t}-1}\right)\right\}^{1 / 2}\right.} \\
& \left.\quad \times *\left\{\beta_{\mathrm{Et}}^{2} * \operatorname{var}\left(\mathrm{E}_{\mathrm{t}-1}\right)+\operatorname{var}\left(\zeta_{\mathrm{Et}}\right)\right\}^{1 / 2}\right] .
\end{aligned}
$$




\section{TABLE 2}

Model Fit Indices of the Different Models Considered

\begin{tabular}{lllllll}
\hline & Model & AIC & BIC & SA-BIC & Log-likelihood & Free parameters \\
\hline 1 & AE-simplex unconstrained & $125,921.89$ & $126,323.70$ & $126,113.99$ & $-62,894.94$ & 66 \\
2 & AE-simplex unconstrained $\Theta_{d}=$ free & $125,939.32$ & $126,395.91$ & $126,157.61$ & $-62,894.66$ & 75 \\
3 & AE-simplex $\Theta_{a}=0$ & $125,916.14$ & $126,275.33$ & $126,087.86$ & $-62,899.07$ & 59 \\
4 & AE-simplex $\Theta_{a}=0 \quad \Theta_{e}=$ equal & $125,911.88$ & $126,234.54$ & $126,066.13$ & $-62,902.94$ & 53 \\
\hline
\end{tabular}

\section{TABLE 3}

Estimates of the Genetic Variance $\left(V_{A}\right)$ and Environmental Variance $\left(V_{E}\right)$ for Each Age Bin

\begin{tabular}{lrrrlrrrrr}
\hline Age & $14-15$ & $16-17$ & $18-19$ & $20-21$ & $22-23$ & $24-25$ & $26-27$ & $28-29$ & $30-31$ \\
\hline $\mathrm{V}_{\mathrm{A}}$ & 282.03 & 282.03 & 286.56 & 286.559 & 300.93 & 299.10 & 288.68 & 309.32 & 285.26 \\
$\mathrm{~V}_{\mathrm{E}}$ & 215.49 & 222.11 & 262.94 & 278.53 & 284.14 & 336.32 & 299.08 & 302.82 & 323.61 \\
$\mathrm{~h}^{2}$ & 0.57 & 0.58 & 0.52 & 0.52 & 0.52 & 0.47 & 0.49 & 0.51 & 0.47 \\
$\mathrm{e}^{2}$ & 0.19 & 0.19 & 0.26 & 0.27 & 0.28 & 0.34 & 0.30 & 0.30 & 0.33 \\
error $^{2}$ & 0.24 & 0.23 & 0.22 & 0.21 & 0.20 & 0.19 & 0.21 & 0.19 & 0.20 \\
\hline
\end{tabular}

Note: The table includes the standardized genetic variance component $\left(\mathrm{h}^{2}\right)$ and the standardized environmental variance components, broken down into environmental $\left(\mathrm{e}^{2}\right)$ and error components (denoted error $^{2}$ ). Note that the error ${ }^{2}$ terms are equal to the standardized unshared environmental age specific components (raw variance terms in $\Theta_{E}$ ).

\section{Results}

The phenotypic correlations between age bins are between $\sim 0.40$ and $\sim 0.70$ (Table 1). Females scored significantly higher at all ages (Table 1), as often reported in previous studies (Roberts et al., 2006; Soto et al., 2011). We observed a significant decrease in mean values with age $\left(\chi^{2}(16)=301.2, p<.001\right)$. The twin correlations ranged from $\sim 0.61$ to $\sim 0.66$ in the MZ pairs, and from $\sim 0.29$ to $\sim 0.10$ in the $\mathrm{DZ}$ pairs (Table 1 ). The twin correlations suggested large genetic effects and the absence of shared environmental effects. The twin correlations at ages 24$25,28-39$, and 30-31 suggested dominance, as twice the $\mathrm{DZ}$ twin correlation is appreciably lower than the $\mathrm{MZ}$ twin correlation. The full ADE simplex model failed to converge (presumably due to missingness in the data) and does not feature in Table 2. We fitted a model in which only the age-specific dominance variance $\operatorname{var}\left(\tau_{\mathrm{Dt}}\right)$ was included (i.e., without the auto-regression terms) and this model did not fit better than the AE simplex model (see Table 2). We also considered the ADE simplex without age specific $\mathrm{D}$ variance, but this model did not converge, and likewise does not feature in Table 2. We observed that the estimated variances $\operatorname{var}\left(\tau_{\mathrm{At}}\right)$ were very small and not significant at any age. In addition, we noted that the estimated variances $\operatorname{var}\left(\tau_{\mathrm{Et}}\right)$ were very similar in magnitude. Constraining $\operatorname{var}\left(\tau_{\mathrm{At}}\right)$ to zero and $\operatorname{var}\left(\tau_{\mathrm{Et}}\right)$ to be equal was judged to be acceptable on the basis of the AIC, BIC, and SA-BIC (Table 2).

Table 3 contains the variance estimates and the standardized variance components, including a breakdown into environmental and error variance (i.e., occasion specific environmental). Heritability estimates showed a decreasing trend starting at 0.57 (age 14-15) and ending at 0.47 (age $30-31$ ). The decrease in heritability was due to an increase in the environmental variance (from about $\sim 215$ at age 14-16 to $\sim 323$ at age $30-32$ ). The genetic variance in neuroticism remained very similar between ages 14 and 31 (from $\sim 282$ at age $14-15$ to 285 at age $30-31$; Table 3 ). The estimated genetic covariance matrix $\Sigma_{\mathrm{A}}$ revealed high genetic stability between the ages of 14 and 31 . The genetic correlations between adjacent ages increased with age, as shown in Figure 1; for example, the correlation between consecutive ages ranged from 0.84 (age 14-15 to age 16-17) to 0.97 (age 28-29 to age 30-31). The genetic innovation variances, $\operatorname{var}\left(\zeta_{\mathrm{At}}\right)$, at ages $24-25,28-29$, and 30-31 were not greater than zero ( $p$ values: $p_{24-25}=.47, p_{28-29}=.65$ and $\left.p_{30-31}=.26\right)$. Dropping the innovation variances did not lead to a deterioration in model fit, $\chi^{2}(3)=0.62, p=.88$. This suggests a nearly perfect genetic stability between ages 24 and 31.

As shown in Figure 2, the environmental covariance matrix $\Sigma_{\mathrm{E}}$ revealed relatively low environmental stability. The uncorrected environmental correlations between ages 1415 and $16-17$ and between ages $28-29$ and 30-31 are 0.31 and 0.57 , respectively. The genetic stability was appreciably greater than the environmental stability. Table 3 contains the proportion of genetic variance $\left(h^{2}\right)$, and the proportions of environmental and error variance (Figure 3). Taking one minus the proportion of error as an index of reliability, the results in Table 3 implied a reliability between 0.75 and 0.81 . Again, assuming the age-specific environmental effects were completely attributable to measurement error, we calculated the correlations corrected for this error variance. As expected, the environmental stability was appreciably higher: the correlation between ages 14-15 and 16-17 was 0.70 , and between ages 28-29 and 30-31 was 0.93 . The environmental stability increased with age because the 


\begin{tabular}{|c|c|c|c|c|c|c|c|c|}
\hline Age $14-16$ & & & 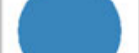 & 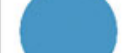 & 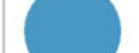 & 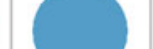 & 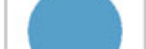 & 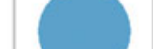 \\
\hline 0.84 & Age $16-18$ & & & & & & & \\
\hline 0.7 & 0.84 & Age $18-20$ & & & & & & \\
\hline 0.65 & 0.78 & 0.93 & Age $20-22$ & & & & & \\
\hline 0.58 & 0.7 & 0.83 & 0.89 & Age 22 - 24 & & & & \\
\hline 0.58 & 0.69 & 0.82 & 0.88 & 0.99 & Age $24-26$ & & & \\
\hline 0.55 & 0.66 & 0.78 & 0.84 & 0.95 & 0.96 & Age $26-28$ & & \\
\hline 0.55 & 0.66 & 0.78 & 0.84 & 0.94 & 0.95 & 0.99 & Age $28-30$ & \\
\hline 0.53 & 0.63 & 0.75 & 0.81 & 0.91 & 0.92 & 0.96 & 0.97 & Age $30-32$ \\
\hline
\end{tabular}

\section{FIGURE 1}

(Colour online) Estimates and heat map of genetic correlations across age for neuroticism.

environmental innovation variance $\left(\zeta_{\mathrm{Et}}\right)$ decreased with age and was no longer significant at age $30-31\left(S D\left[\zeta_{\mathrm{E} 30-32}\right]=\right.$ $5.205, \mathrm{t}=1.455, p=.15)$.

\section{Discussion}

Using a cohort sequential twin design, we quantified the genetic and environmental stability in neuroticism. Restructuring the data from measurement occasion into age bins allowed us to estimate age-related changes in genetic and environmental stability of neuroticism in the critical period between ages 14 and 31 years, a period that is characterized by an increase in the phenotypic stability of neuroticism (Roberts \& DelVecchio, 2000; Soto et al., 2011). We found evidence for increasing genetic stability resulting in nearly perfect rank stability after age 24 , that is, genetic correlations approaching unity. When we corrected for measurement error, we also observed substantial environmental stability. Correcting for measurement error provides an upper bound for the environmental stability, where in the literature of- ten the lower bound (i.e., not corrected for measurement error) is reported. It is important to note that correcting for measurement error does not guarantee a high stability as, for example, low transmission and high innovation would also result in a low stability.

The substantial environmental stability is compatible with the observation that life events have a lasting effect on mean neuroticism scores (Jeronimus et al., 2013). Other unique environmental factors that may have long-lasting effects are adverse economic circumstances, which have also been observed to have enduring effects on, for example, externalizing problems (Ramanathan et al., 2013). This result is further consistent with a meta-analysis of a more broadly defined 'personality' phenotype (Briley \& TuckerDrob, 2014). While Briley and Tucker-Drob (2014) used a different methodology to correct for measurement error, their conclusion is similar: correcting for measurement error results in substantial environmental stability and this stability increases with age. Not correcting for measurement error leads to a systematic under appreciation of the amount 


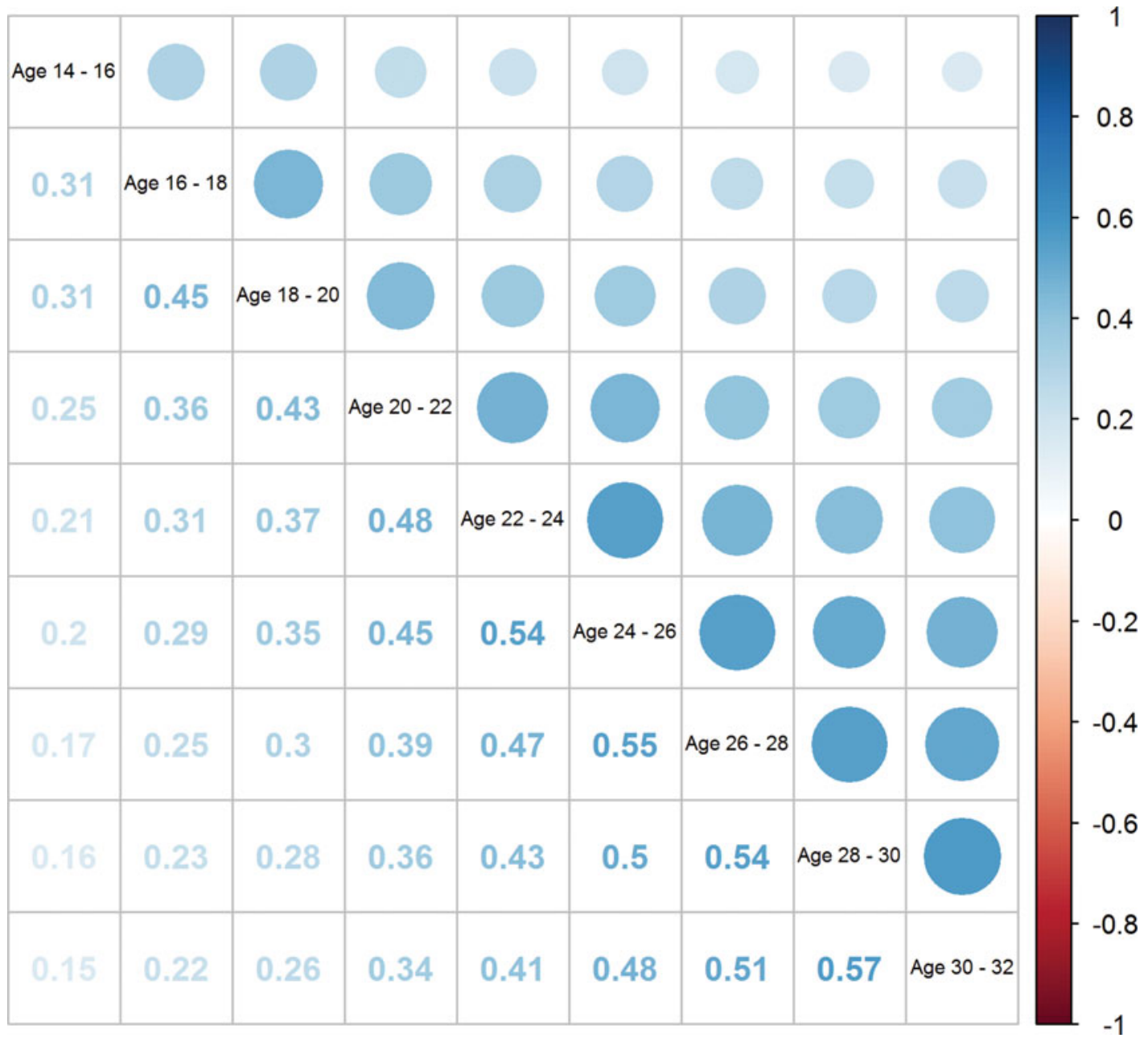

\section{FIGURE 2}

(Colour online) Estimates and heat map of environmental correlations across age for neuroticism.

of environmental stability in neuroticism. This conclusion may generalize to other traits.

The high degree of genetic stability that we observed is in line with previous longitudinal studies of the genetic stability of neuroticism in adolescents and adults (Gillespie et al., 2004a; Viken et al., 1994; Wray et al., 2007). The genetic stability in neuroticism between the ages of 14 and 31 is also similar to the genetic stability reported for symptoms of anxiety and depression, two traits strongly correlated to neuroticism (Gillespie et al., 2004b; Nivard et al., 2014). The implications of the high degree of genetic stability for genome-wide association studies (GWAS) were discussed by Wray et al. (2007). Here, we add that repeated measures can be used to good effect in analyses of the association between neuroticism and polygenic scores or genetic variants such as SNPs or CNVs. Specifically, discarding repeated measures in the regression of neuroticism scores on the genotype scores or genetic variants is not advisable as this will lead to a lower statistical power compared to the regression of all repeated measures. This is comparable to discarding one of the MZ twins in a GWAS including MZ twin pairs (see Minică et al., 2014). Ideally, association between genetic variants and repeated measures of a trait would be carried out in the context of a structural equation model to account for all subtleties in the genetics of a trait across age or repeated measures. However, as computational efficiency is often an issue in genome-wide studies, and the genetic contributions to neuroticism are stable, one could also decide to aggregate repeated measures by taking the mean. Alternatively, the regression of the repeated measures on genotypes (CNVs or SNPs) and polygenic scores can be carried out using generalized estimating equations to account for the dependency among the measurement measures (e.g., see Minică et al., 2015). The inclusion of repeated measures, where available, in GWAS of neuroticism is a possible way to boost power and extend upon current gene finding efforts (de Moor et al., 2015).

Unlike other genetically informative extended pedigree studies (Eaves et al., 1998; Keller et al., 2005; Lake et al., 2000), we found no evidence for a significant contribution 


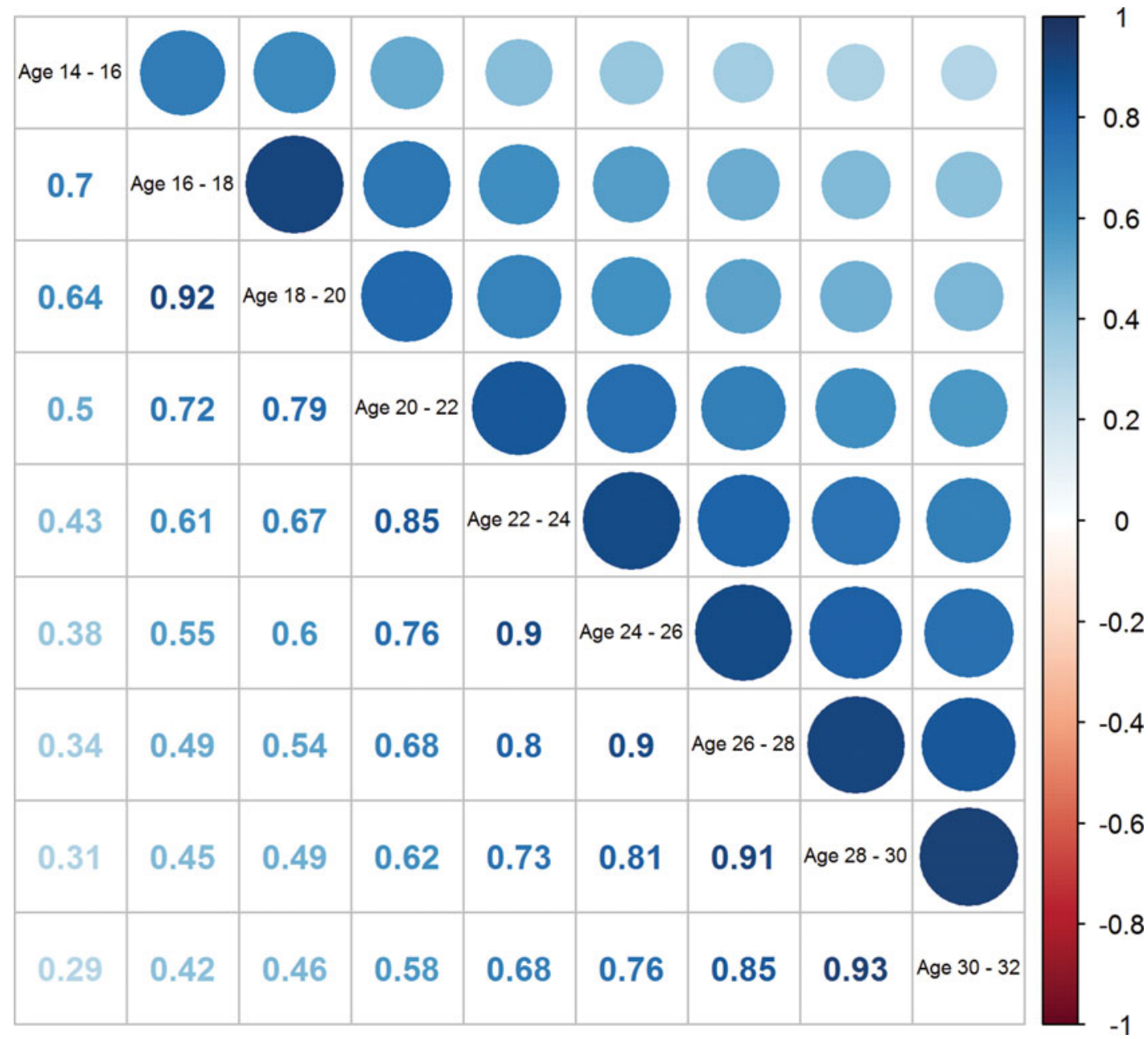

\section{FIGURE 3}

(Colour online) Estimates and heat map of environmental correlations, corrected for age-specific unshared environmental effects (measurement error), across age for neuroticism.

of non-additive genetic variation. Ordering the data into two-year age batches allowed us to estimate the changes in environmental and genetic stability with good temporal resolution. Creating smaller sub-samples per age category may have reduced the power to detect dominance variance and other non-additive effects. Future work, perhaps combining samples from multiple centers as made possible by the neuroticism score harmonization by van der Berg et al. (2014), may make it possible to concurrently estimate the effects of non-additive genetic variance and age-related effects on neuroticism. International collaboration on the genetic of neuroticism has been successful and yielded the first genome-wide significant finding for neuroticism (de Moor et al., 2015). Similar collaborations between twin and family registries could prove useful in further elucidating the genetic and environmental process underlying the development of personality across the lifespan.

\section{Acknowledgments}

Funding was provided by the Netherlands Scientific Organization (NWO) (912-100-20): 'Genetic influences on stability and change in psychopathology from childhood to young adulthood' and the Royal Academy of Sciences Academy Professor Award (PAH/6635).

\section{References}

Birley, A. J., Gillespie, N. A., Heath, A. C., Sullivan, P. F., Boomsma, D. I., \& Martin, N. G. (2006). Heritability and nineteen-year stability of long and short EPQ-R Neuroticism scales. Personality and Individual Differences, 40, 737 747.

Boomsma, D. I., \& Molenaar, P. C. (1987). The genetic analysis of repeated measures. I. Simplex models. Behavior Genetics, $17,111-123$. 
Briley, D. A., \& Tucker-Drob, E. M. (2014). Genetic and environmental continuity in personality development: A metaanalysis. Psychological Bulletin, 140, 1303-1331.

Clark, L. A., Watson, D., \& Mineka, S. (1994). Temperament, personality, and the mood and anxiety disorders. Journal of Abnormal Psychology, 103, 103-116.

de Moor, M. H., van den Berg, S. M., Verweij, K. J., Krueger, R. F., Luciano, M., Vasquez, A. A., ... Boomsma, D. I. (2015). Meta-analysis of genome-wide association studies for neuroticism, and the polygenic association with major depressive disorder. JAMA Psychiatry, 72, 642-650.

Digman, J. M. (1990). Personality structure: Emergence of the five-factor model. Annual Review of Psychology, 41, 417440.

Distel, M. A., Trull, T. J., Willemsen, G., Vink, J. M., Derom, C. A., Lynskey, M., ... Boomsma, D. I. (2009). The fivefactor model of personality and borderline personality disorder: A genetic analysis of comorbidity. Biological Psychiatry, 66, 1131-1138.

Eaves, L. J., Heath, A. C., Neale, M. C., Hewitt, J. K., \& Martin, N. G. (1998). Sex differences and non-additivity in the effects of genes on personality. Twin Research, 1, 131-137.

Enns, M. W., \& Cox, B. J. (1997). Personality dimensions and depression: review and commentary. Canadian Journal of Psychiatry, 42, 274-284.

Floderus-Myrhed, B., Pedersen, N., \& Rasmuson, I. (1980). Assessment of heritability for personality, based on a shortform of the Eysenck Personality Inventory: A study of 12,898 twin pairs. Behavior Genetics, 10, 153-162.

Gillespie, N. A., Evans, D. E., Wright, M. M., \& Martin, N. G. (2004a). Genetic simplex modeling of Eysenck's dimensions of personality in a sample of young Australian twins. Twin Research, 7, 637-648.

Gillespie, N. A., Kirk, K. M., Evans, D. M., Heath, A. C., Hickie, I. B., \& Martin, N. G. (2004b). Do the genetic or environmental determinants of anxiety and depression change with age? A longitudinal study of Australian twins. Twin Research, 7, 39-53.

Jardine, R., Martin, N. G., Henderson, A. S., \& Rao, D. C. (1984). Genetic covariation between neuroticism and the symptoms of anxiety and depression. Genetic Epidemiology, $1,89-107$.

Jeronimus, B. F., Ormel, J., Aleman, A., Penninx, B. W., \& Riese, H. t. (2013). Negative and positive life events are associated with small but lasting change in neuroticism. Psychological Medicine, 43, 2403-2415.

Keller, M. C., Coventry, W. L., Heath, A. C., \& Martin, N. G. (2005). Widespread evidence for non-additive genetic variation in Cloninger's and Eysenck's personality dimensions using a twin plus sibling design. Behavior Genetics, 35, 707721.

Kendler, K. S., Kessler, R. C., Neale, M. C., Heath, A. C., \& Eaves, L. J. (1993). The prediction of major depression in women: Toward an integrated etiologic model. American Journal of Psychiatry, 150, 1139-1148.

Lake, R. I., Eaves, L. J., Maes, H. H., Heath, A. C., \& Martin, N. G. (2000). Further evidence against the environmental transmission of individual differences in neuroticism from a collaborative study of 45,850 twins and relatives on two continents. Behavior Genetics, 30, 223-233.

Ligthart, L., \& Boomsma, D. I. (2012). Causes of comorbidity: pleiotropy or causality? Shared genetic and environmental influences on migraine and neuroticism. Twin Research and Human Genetics, 15, 158-165.

Loehlin, J. C., McCrae, R. R., Costa, P. T., \& John, O. P. (1998). Heritabilities of common and measure-specific components of the Big Five personality factors. Journal of Research in Personality, 32, 431-453.

Mackintosh, M. A., Gatz, M., Wetherell, J. L., \& Pedersen, N. L. (2006). A twin study of lifetime generalized anxiety disorder (GAD) in older adults: Genetic and environmental influences shared by neuroticism and GAD. Twin Research and Human Genetics, 9, 30-37.

McCrae, R. R., \& Costa Jr, P. T. (1997). Personality trait structure as a human universal. American Psychologist, 52, 509516.

McCrae, R. R., Costa, P. T., de Lima, M. P., Simoes, A., Ostendorf, F., Angleitner, A., ... Piedmont, R. L. (1999). Age differences in personality across the adult life span: parallels in five cultures. Developmental Psychology, 35, 466477.

Middeldorp, C., Cath, D., van den Berg, S. M., Beem, A., Van Dyck, R., \& Boomsma, D. I. (2006). The association of personality and anxious and depressive psychopathology. In C. Turhan (Ed.), The biological basis of personality and individual differences (pp. 251-272). New York: Guilford Press.

Middeldorp, C. M., Cath, D. C., Van Dyck, R., \& Boomsma, D. I. (2005). The co-morbidity of anxiety and depression in the perspective of genetic epidemiology. A review of twin and family studies. Psychological Medicine, 35, 611-624.

Middeldorp, C. M., De Moor, M. H. M., McGrath, L. M., Gordon, S. D., Blackwood, D. H., Costa, P. T., ... Boomsma, D. I. (2011). The genetic association between personality and major depression or bipolar disorder. A polygenic score analysis using genome-wide association data. Translational Psychiatry, 1, e50.

Minică, C. C., Boomsma, D. I., Vink, J. M., \& Dolan, C. V. (2014). MZ twin pairs or MZ singletons in population family-based GWAS; More power in pairs. Molecular Psychiatry, 19, 1154-1155.

Minică, C. C., Dolan, C. V., Kampert, M. M., Boomsma, D. I., \& Vink, J. M. (2015). Sandwich corrected standard errors in family-based genome-wide association studies. European Journal of Human Genetics, 23, 388-394.

Nivard, M. G., Dolan, C. V., Kendler, K. S., Kan, K. J., Willemsen, G., van Beijsterveldt, C. E., ... Boomsma, D. I. (2014). Stability in symptoms of anxiety and depression as a function of genotype and environment: A longitudinal twin study from ages 3 to 63 years. Psychological Medicine, $4,1-11$.

Ramanathan, S., Balasubramanian, N., \& Krishnadas, R. (2013). Macroeconomic environment during infancy as a possible risk factor for adolescent behavioral problems. JAMA Psychiatry, 70, 218-225. 
Rettew, D. C., Vink, J. M., Willemsen, G., Doyle, A., Hudziak, J. J., \& Boomsma, D. I. (2006). The genetic architecture of neuroticism in 3,301 Dutch adolescent twins as a function of age and sex: A study from the Dutch twin register. Twin Research and Human Genetics, 9, 24-29.

Roberts, B. W., \& DelVecchio, W. F. (2000). The rank-order consistency of personality traits from childhood to old age: A quantitative review of longitudinal studies. Psychological Bulletin, 126, 3-25.

Roberts, B. W., Walton, K. E., \& Viechtbauer, W. (2006). Patterns of mean-level change in personality traits across the life course: A meta-analysis of longitudinal studies. Psychological Bulletin, 132, 1-25.

Roberts, S. B., \& Kendler, K. S. (1999). Neuroticism and selfesteem as indices of the vulnerability to major depression in women. Psychological Medicine, 29, 1101-1109.

Schmitt, D. P., Allik, J., McCrae, R. R., \& Benet-Martinez, V. (2007). The geographic distribution of Big Five personality traits patterns and profiles of human self-description across 56 nations. Journal of Cross-Cultural Psychology, 38, 173212.

Smits, I. A., Dolan, C. V., Vorst, H., Wicherts, J. M., \& Timmerman, M. E. (2011). Cohort differences in Big Five personality factors over a period of 25 years. Journal of Personality and Social Psychology, 100, 1124-1138.

Soto, C. J., John, O. P., Gosling, S. D., \& Potter, J. (2011). Age differences in personality traits from 10 to 65: Big Five domains and facets in a large cross-sectional sample. Journal of Personality and Social Psychology, 100, 330-348.

van den Berg, S. M., de Moor, M. H., McGue, M., Pettersson, E., Terracciano, A., Verweij, K. J., ... Boomsma, D. I. (2014). Harmonization of neuroticism and extraversion phenotypes across inventories and cohorts in the Genetics of Personality Consortium: An application of item response theory. Behavior Genetics, 44, 295-313.

Viken, R. J., Rose, R. J., Kaprio, J., \& Koskenvuo, M. (1994). A developmental genetic analysis of adult personality: Extraversion and neuroticism from 18 to 59 years of age. Journal of Personality and Social Psychology, 66, 722-730.

Vukasović, T., \& Bratko, D. (2015). Heritability of personality: A meta-analysis of behavior genetic studies. Psychological Bulletin, 141, 769-785.

Wilde, G. J. S. (1970). Neurotische labiliteit gemeten volgens de vragenlijstmethode [The questionnaire method as a means of measuring neurotic instability]. Amsterdam: F. Van-Rossen.

Willemsen, G., Vink, J. M., Abdellaoui, A., den Braber, A., van Beek, J. H., Draisma, H. H., ... Boomsma, D. I. (2013). The adult Netherlands twin register: Twenty-five years of survey and biological data collection. Twin Research and Human Genetics, 16, 271-281.

Wray, N. R., Birley, A. J., Sullivan, P. F., Visscher, P. M., \& Martin, N. G. (2007). Genetic and phenotypic stability of measures of neuroticism over 22 years. Twin Research and Human Genetics, 10, 695-702. 